\title{
Creativity in Citizen Cyberscience
}

\author{
CHARLENE JENNETT, University College London, UK
}

LAURE KLOETZER, University of Neuchatel, Switzerland

ANNA L. COX, University College London, UK

DANIEL SCHNEIDER, University of Geneva, Switzerland

EMILY COLLINS, University College London, UK

MATTIA FRITZ, University of Geneva, Switzerland

MICHAEL J. BLAND, University Paris Descartes, France

CINDY REGALADO, University College London, UK

IAN MARCUS, University Paris Descartes, France

HANNAH STOCKWELL, University College London, UK

LOIUSE FRANCIS, University College London, UK

ELEANOR RUSACK, UNITAR/UNOSAT, Switzerland

IOANNIS CHARALAMPIDIS, CERN, Switzerland

\begin{abstract}
An interview study was conducted to explore volunteers' experiences of creativity in citizen cyberscience. Participants were recruited from 4 projects: GeoTag-X, Virtual Atom Smasher, Synthetic Biology, and Extreme Citizen Science. Ninety-six interviews were conducted in total: 86 with volunteers (citizen scientists) and 10 with professional scientists. The resulting thematic analysis revealed that volunteers are involved in a range of creative activities, such as discussing ideas, suggesting improvements, gamification, artwork, creative writing, and outreach activities. We conclude that the majority of creative products are community-related. Creativity in citizen cyberscience is a collective process: volunteers create within a project and a community, both for themselves and for others.
\end{abstract}




\section{INTRODUCTION}

Citizen science is a form of research collaboration where members of the general public voluntarily work with professional scientists to address real-world problems (Cohn, 2008). Citizen science enables scientists to have a larger workforce to collect and analyse research data. Another benefit, not always anticipated, is that sometimes volunteers think "outside of the box", bringing their own unique perspective to scientific problems and generating new ideas (Dickinson, 2011). This can result in new scientific discoveries that may not have been possible if not for the creative thinking of volunteers. Famous examples of this include Galaxy Zoo's "Pea Hunt" (Cardamone et al., 2009) and Foldit's HIV enzyme discovery (Cooper et al., 2011). However, could there be other kinds of creative outputs from volunteers that are less ground-breaking, but also valuable for a project's success? In our research we aimed to understand the range of creative activities that volunteers are involved in and the factors that motivate volunteers to be creative. We start by describing previous work on citizen cyberscience and creativity. Next we describe our research study, where we interviewed 86 volunteers and 10 scientists about their experiences. Finally, we discuss our findings and new insights that we have gained for understanding creativity in citizen cyberscience.

\section{BACKGROUND}

\subsection{What is Citizen Cyberscience?}

There are many different kinds of citizen science. Bonney et al. (2009) identified 3 types based on the extent of volunteers' involvement: contributory, collaborative and co-created. Wiggins and Crowston (2011) identified 5 types, considering the primary project goals and the importance of the physical environment to participation: action, conservation, investigation, virtual and education. In this article, we specifically focus on citizen cyberscience - these are citizen science projects facilitated by the Internet. Haklay (2013) identified 3 categories of citizen cyberscience: volunteer computing, volunteer thinking, and participatory sensing.

In volunteer computing, participants install software on their personal computers to enable projects to utilize their unused processing capacity. The Berkeley Open Infrastructure for Network Computing system $\left(B O I N C^{1}\right)$ allows data to be processed for a range of projects, including physics, climate change, and biology.

In volunteer thinking, participants typically visit a website where they are presented with data and they are trained to analyse the data according to a certain research protocol. Examples include classifying galaxies (Galaxy $\left.Z_{o o}^{2}\right)$, folding proteins $\left(\right.$ Foldit $\left.^{3}\right)$, and transcribing weather information (Old Weather ${ }^{4}$ ). In addition to science research, volunteer thinking projects can be

\footnotetext{
${ }^{1}$ https://boinc.berkeley.edu/

2 https://www.galaxyzoo.org/

${ }^{3} \mathrm{https://fold.it/portal//}$

4 https://www.oldweather.org/
} 
found within humanities research. For example, volunteers can transcribe unstudied manuscripts written by the philosopher Jeremy Bentham (Transcribe Bentham ${ }^{5}$ ).

In participatory sensing, participants typically download a mobile phone app which allows them to collect data by utilizing sensors that are already integrated in their mobile phone, e.g. Wifi, GPS receivers, camera, microphone. For example, volunteers can collect data about local animal species (Project $N_{o a h}{ }^{6}$ ), and noise levels (WideNoise ${ }^{7}$ ). Sometimes volunteers are also asked to submit behavioural information, such as rating how happy they feel $\left(\right.$ Mappiness $^{8}$ ), or tweeting errors they had experienced that day (Errordiary ${ }^{9}$ ).

Usually citizen cyberscience projects are designed by scientists and volunteers are asked to assist in some way. Projects that work in the opposite way - where citizens design their own projects and the scientists' role is to facilitate this work - are known as extreme citizen science. An example of this is the Sapelli project, where scientists worked with Congo tribes to design a mobile app to help them map parts of the rainforest that were important to them (Vitos et al., 2013). Another example is Science in the City, where scientists worked with local community groups in the UK who were concerned about air quality, helping them to collect data and to map the air quality in their local area (Mapping for Change, 2014).

\subsection{Creativity as a Collective Process}

Currently there is a paradigm shift from an individual-based to social-based understanding of creativity. The development and the widespread use of the Internet is key to this transformation. Cloud computing provides a variety of avenues for social creativity and collaborative learning because it enables endless ideas, thoughts, and knowledge to be shared, created, and inspired (Kop \& Carroll, 2012). Literat et al. (2016) explain that "online participation is associated with heightened connectivity and an unprecedented potential for sharing information, connecting people and ideas usually kept apart, and facilitating collaboration both within the digital world and beyond it. These features not only impact creativity as a phenomenon but essential redefine it..."

Researchers have started to investigate social creativity in a variety of different online contexts. For example, Maciuliene and Skarzauskiene (2016) studied online communities that use social technologies to encourage collective decision making, creativity, entrepreneurship and cooperation. They found that community members emphasised the importance of communication culture, respect and trust.

Kop and Carroll (2012) studied participants of a Massive Open Online Course (MOOC). They found that it takes time for learners to build confidence and to experience the spark that

\footnotetext{
${ }^{5}$ http://blogs.ucl.ac.uk/transcribe-bentham/

${ }^{6} \mathrm{http}: / /$ www.projectnoah.org/

${ }^{7} \mathrm{http}: / /$ cs.everyaware.eu/event/widenoise

$8 \mathrm{http://www.mappiness.org.uk/}$

9 http://www.errordiary.org/
} 
inspires them to create artefacts for the course community. Learners must feel comfortable in their learning environment and have a certain level of trust in their fellow participants. Also, when learners saw others being creative and interacting socially, via micro-blogging tools and discussion forums, this inspired them to create and share.

\subsection{Creativity in Citizen Cyberscience}

There are a few famous examples of citizen-led discoveries in citizen cyberscience. The first example is the "Pea Hunt" in Galaxy Zoo - an online project where volunteers classify images of galaxies. A group of Galaxy Zoo volunteers noticed several images containing unusual "green pea" shapes and decided to start collecting them. The science team originally believed that the greenish appearance was due to a glitch of the imaging apparatus. However, they decided to look into it more deeply because of the volunteers' interest and found out that these green peas were actually a new class of star-forming galaxies (Cardamone et al., 2009).

Another example of volunteers making scientific breakthroughs occurred in Foldit - an online project where volunteers collaborate and compete to fold protein structures. A group of Foldit gamers managed to uncover the protein structure of a HIV enzyme that had previously stumped scientists for over a decade (Cooper et al., 2011).

Tinati et al. (2015) suggest that citizen-led discovery is facilitated by task workflows which encourage discussion and timely support from science team members. However, what about other kinds of creativity that do not result in scientific discoveries? In our research we argue that there could there be other kinds of creative outputs from volunteers that are less groundbreaking, but also valuable for a project's success.

In an earlier study, we interviewed 39 volunteers across 15 different citizen cyberscience projects (Jennett et al., 2016). Our analysis revealed that the majority of creative products were community-related (see Figure 1). The forum was a key space where ideas and creative works were shared. Volunteers proposed suggestions and built tools and resources in order to solve project problems. Community-enhanced gamification, forum discussions and artwork, provided excitement and enhanced the life of the community. Volunteers also shared the project with others via outreach activities, providing new ways for the community to grow. 


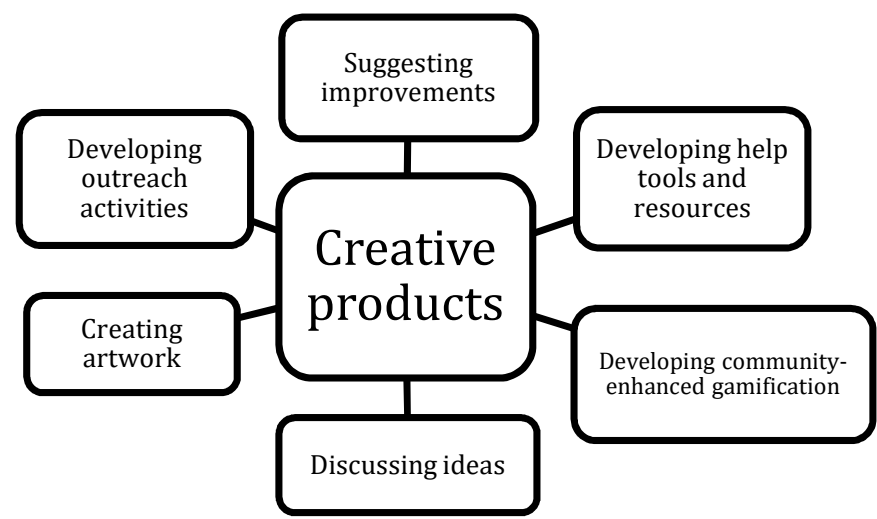

Figure 1. Thematic map of volunteers' creative products (Jennett et al., 2016).

\section{INTERVIEW STUDY}

The aim of the current interview study was to build upon our previous work (Jennett et al., 2016), exploring the different kinds of creativity that volunteers experience in citizen cyberscience. Our sample consisted of volunteers and scientists from the 4 Citizen Cyberlab pilot projects (presented in sections 4 and 5):

1. GeoTag-X

2. Virtual Atom Smasher (VAS)

3. Synthetic Biology - iGEM competition

4. Extreme Citizen Science - including Do-It-Yourself (DIY) and Air Quality Monitoring (AQM)

Together these pilot projects represent different kinds of citizen cyberscience. In some projects volunteers only take part in data analysis (GeoTag-X, VAS), while in other projects volunteers are involved in generating research questions (DIY) and the whole research process (AQM). Some projects involve social aspects, such as team work (iGEM). Some projects involve game-like aspects (VAS). Whereas some projects involve mostly online participation (GeoTag-X, VAS), other projects involve meeting volunteers in person (iGEM, DIY, AQM).

For the purposes of our analysis, we divided the projects into two main categories - virtual citizen science and community-based citizen science (see Table 1), according to the main activities offered in the projects. In the virtual citizen science projects, the volunteers are asked to complete specific tasks online (analyzing pictures or tuning parameters). These tasks are designed by the project team or a team of expert volunteers. In the community-based citizen science projects, the topic and research process are jointly designed, and the volunteers take responsibility of collecting data, analyzing data, and communicating the results. 
We designed an interview script to explore volunteers' experiences of creativity as well as other topics, such as their motivations and learning. Questions included:

- "Can you think of any examples where you have been creative? Or other volunteers have been creative? What happened and how did you feel"

- "How important was the community in this creative work?"

- "Does technology play a role in your creative work in any way?"

Working in collaboration with the scientists leading/facilitating the pilot projects, we tailored the interview script according to each project. We also decided to interview the scientists themselves to get their impressions of volunteers' creativity.

\section{Table 1. Summary of interview data collected.}

\begin{tabular}{|c|c|c|c|c|c|}
\hline & \multicolumn{2}{|c|}{$\begin{array}{l}\text { VIRTUAL CITIZEN } \\
\text { SCIENCE }\end{array}$} & \multicolumn{3}{|c|}{ COMMUNITY-BASED CITIZEN SCIENCE } \\
\hline & \multirow[t]{2}{*}{ GeoTag-X } & \multirow{2}{*}{$\begin{array}{l}\text { Virtual } \\
\text { Atom } \\
\text { Smasher }\end{array}$} & \multirow{2}{*}{$\begin{array}{l}\text { Synthetic } \\
\text { Biology - } \\
\text { iGEM } \\
\text { competition }\end{array}$} & \multicolumn{2}{|c|}{ Extreme Citizen Science } \\
\hline & & & & Do-It Yourself & $\begin{array}{l}\text { Air Quality } \\
\text { Monitoring }\end{array}$ \\
\hline $\begin{array}{l}\text { Interviews with } \\
\text { volunteers (citizen } \\
\text { scientists) }\end{array}$ & $\begin{array}{l}13 \\
\text { interviews: } 4 \\
\text { volunteer- } \\
\text { developers, } 9 \\
\text { volunteer- } \\
\text { analysers }\end{array}$ & $\begin{array}{l}9 \\
\text { interviews }\end{array}$ & $\begin{array}{l}26 \text { interviews: } \\
15 \text { from iGEM } \\
2014,11 \text { from } \\
\text { iGEM } 2015\end{array}$ & $\begin{array}{l}23 \text { interviews: } 7 \\
\text { from Explorers of } \\
\text { the World } \\
\text { playshops } 2014,5 \\
\text { from Explorers of } \\
\text { the World } \\
\text { playshops } 2015,7 \\
\text { from kite-mapping } \\
\text { workshop, } 8 \text { from } \\
\text { Public Lab }\end{array}$ & $\begin{array}{l}13 \text { interviews } \\
\text { with participants } \\
\text { from various } \\
\text { AQM projects, } \\
\text { e.g. Barbican, } \\
\text { Westway, } \\
\text { Streatham, } \\
\text { Silvertown, } \\
\text { Catford, Hackney }\end{array}$ \\
\hline $\begin{array}{l}\text { Interviews with } \\
\text { scientists (project } \\
\text { leaders/facilitators) }\end{array}$ & 2 scientists & 2 scientists & 2 scientists & 1 scientist & 3 scientists \\
\hline
\end{tabular}

We conducted 96 interviews in total: 86 with volunteers (citizens) and 10 with scientists (project leaders/facilitators). The interviews were semi-structured, conducted over Skype, and typically lasted for 30-60 minutes. Audio recordings were transcribed and analysed using thematic analysis - a qualitative research method for identifying, analysing, and reporting patterns (themes) within data (Braun \& Clarke, 2006).

In the sections that follow we briefly describe each pilot project and present the main themes from our analysis. For the purposes of this article, we report results related to creativity only. The themes reflect all activities that have been quoted as "creative" by any of the volunteers. 


\section{VIRTUAL CITIZEN SCIENCE}

In this section we describe the two virtual citizen science projects: GeoTag-X and Virtual Atom Smasher. Then we present creativity themes for each project. Finally, we discuss similarities between the themes and propose 4 main motivations for volunteers' creativity.

\subsection{Pilot Projects}

\subsubsection{GeoTag-X}

The GeoTag-X pilot, developed by UNITAR/UNOSAT, aims to teach volunteers to perform in-depth analyses of media coming out of a disaster. This involves recognizing the important information in a photo and creating relevant, structured datasets that can be used by those working on the ground in the disaster response. Over 20 projects have been launched on the GeoTag-X website ${ }^{10}$. These projects cover different disaster-related events, such as floods, and earthquakes, along with more slow moving events, such as droughts, and pollution.

GeoTag-X volunteers can be divided into two categories:

- $\quad$ volunteer-developers, who help to develop the series of questions and multiple choice answers for one (or more) of the GeoTag-X projects; and

- volunteer-analysers, anyone that visits the GeoTag-X website and analyses photos for one (or more) of the GeoTag-X projects.

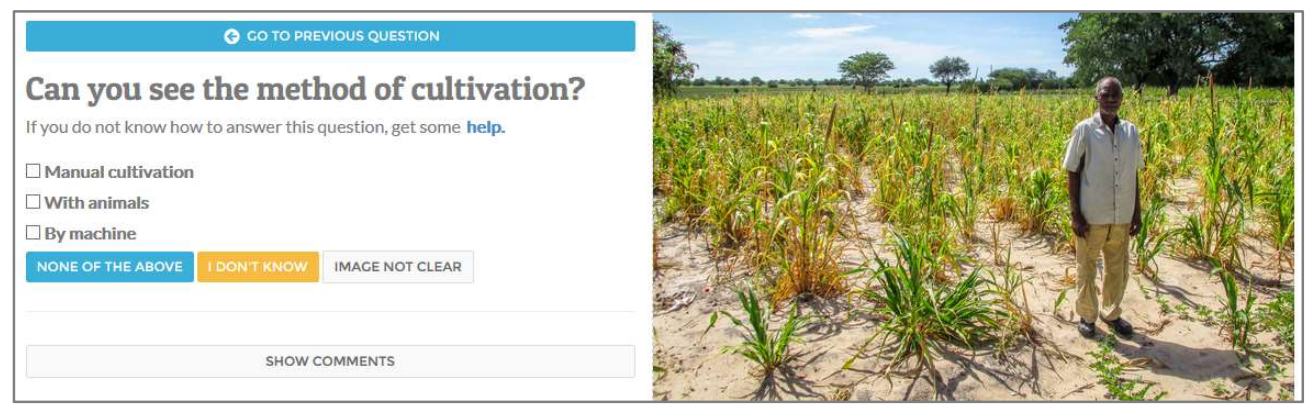

Figure 2. Screenshot of GeoTag-X project “Crop Identification for Drought”.

Typically, volunteer-developers have some expertise in disaster response. They are in regular communication with the lead researcher during the project's development via Skype, email, and the Github forum. They are also involved in testing early prototypes.

In comparison, no prior knowledge of disaster response is necessary to be a volunteeranalyser. Each GeoTag-X project has a tutorial to guide volunteer-analysers through its series

${ }^{10} \mathrm{http}: / /$ GeoTag-X.org/ 
of questions and what to look out for in photos. A help button is also available in case volunteers would like advice for a particular question. See Figure 2 for a screenshot.

\subsubsection{Virtual Atom Smasher}

The Virtual Atom Smasher (VAS) pilot, developed by CERN, is an interactive educational game in which players try to "tune" a simulation of high-energy particle collisions to give an optimal description of a chosen set of reference data, while simultaneously learning about particle physics. The game is available to play on the VAS website ${ }^{11}$. See Figure 3 for a screenshot.

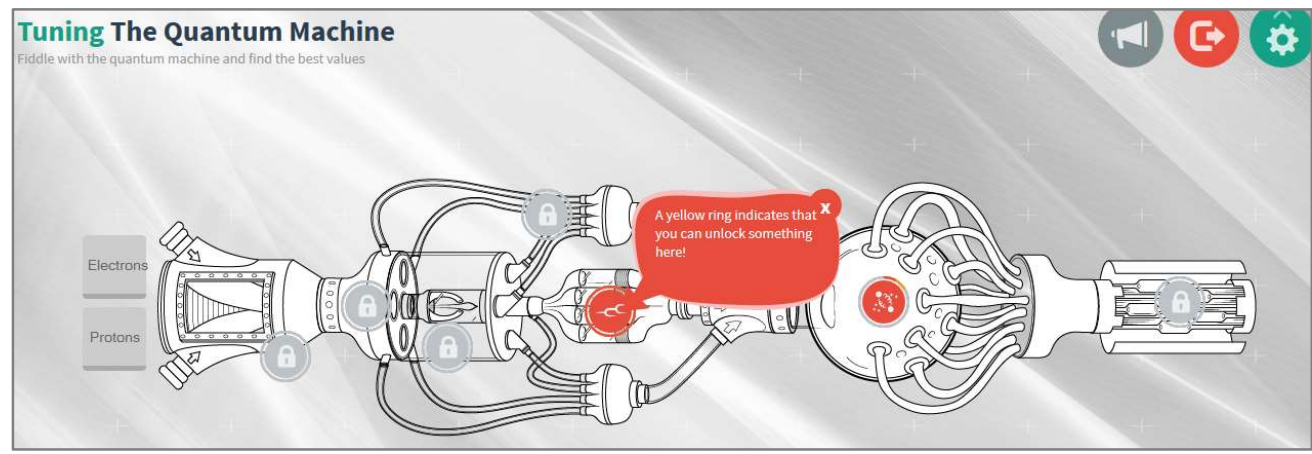

Figure 3. Screenshot of quantum machine with unopened challenges in VAS.

No prior knowledge of particle physics is needed for players to get started in running simulations and tuning parameters. Help videos are available to guide players in how to use the interface. Players also have options to "read more" and "take a course" if they would like to find out more about the particle physics involved in the simulation.

\subsection{Creativity Findings}

In the presentation of our findings, we will focus on the convergences between the two virtual citizen science projects. Figure 4 offers an overview of creativity themes for the two projects. We identify 2 main findings. First, the two virtual citizen science projects offered expert volunteers the opportunity to contribute to the design of the project or to customize parts of the project, and this was a main source of creativity. Second, most volunteers expressed that creativity was not important (and maybe not desirable) in citizen science projects. Tasks should be performed in a reliable way, and creativity is associated with a lack of discipline. However, there can be some creative thinking associated to these basic tasks, which we will describe below.

\section{${ }^{11} \mathrm{http}: / /$ test4theory.cern.ch/vas/}




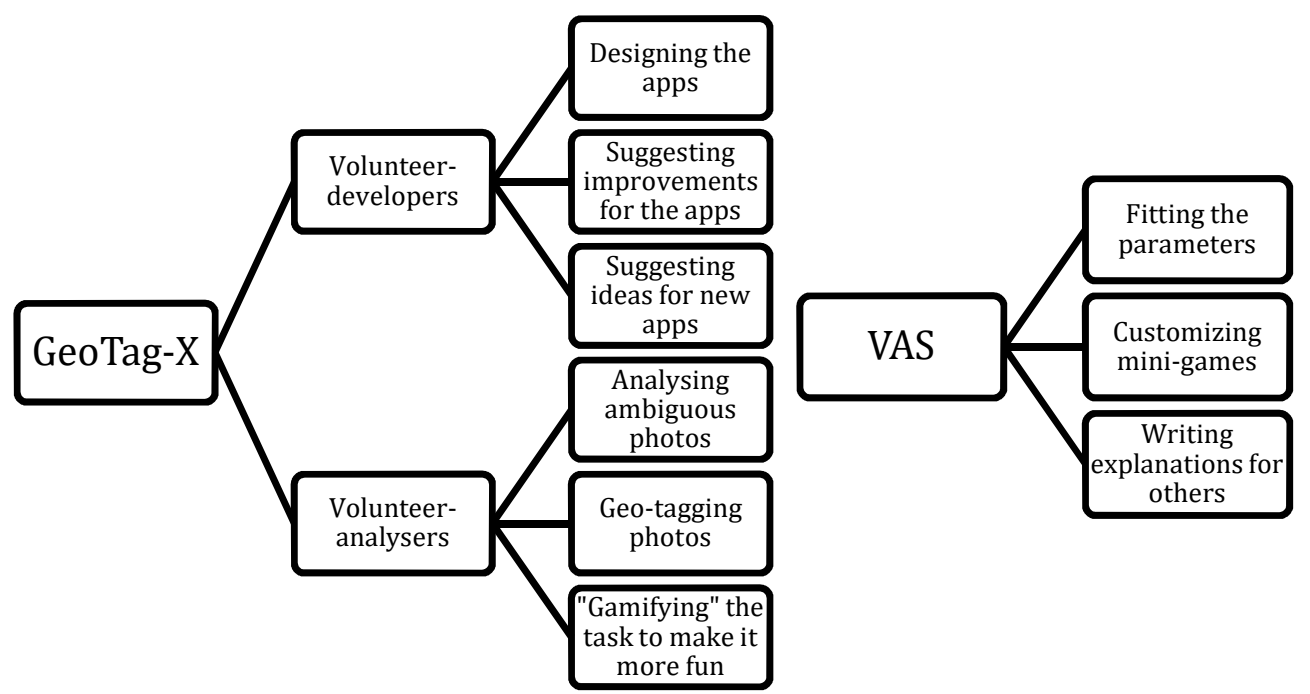

Figure 4. Creativity themes for GeoTag-X and Virtual Atom Smasher (VAS).

\subsubsection{Expert volunteers engaged in the design or customization of the project feel creative in their work}

In both projects, giving volunteers the opportunity to contribute to the design of the projects was appreciated as one main source of creativity. In Geo-Tag X, volunteer-developers felt that they were most creative when they were designing the apps. They had to transform their expertise in disaster response into questions that could be answered with certainty by volunteers. They had to think about what kinds of information would be useful to extract from the photos. They also needed to think about how they could phrase these questions in a way that would be easy for a lay-person to understand, and the different multiple choice options that they would need to be provide for users. For example, one volunteer said: "I guess my creativity has been in trying to assess the photos and format what I see into the questions [...] I put it into a format where it's not too complicated for a layperson to look at it and we could easily have some, do their eyes seem sunken, are there dark circles under the eyes, are they smiling, are they not smiling, you know something that would gather better data for what I see from a medical standpoint."

Typically this was an iterative process. A few volunteer-developers worked together to draft a set of initial questions and options. This was then tested out by other volunteers, who suggested improvements, and then a new version was created. One of the scientists said that she was impressed by volunteers' analytical skills and their team work in creating the final wording of questions and answers for each app: "I think that even people who have not got that much interest in designing their own programs, they still tend to go "oh why is that question worded in that way? I think that the question should be worded in some other way". 
And so I think that it encourages people to strategically think about questions, and to think about how they might choose to word questions differently [...] for example in that Github forum, there are already people saying "I would like to see this question worded that way" and there have been changes to the site based on that..."

Volunteer-developers also showed creativity by suggesting ideas for future projects. One of the scientists explained that volunteers were often excited about the potential of GeoTag-X after they tried it out: "...that photo task brought a sense of understanding, what it was that the technology does, and then that mental leap of "what else could that do? What could it relate to that I'm involved in?" and that leads to the creative process. A load of people freely in their mind think "are there other potentials?" and then they come up with something. And that spark of excitement where people suddenly go "oh that could be used for this", and that's really exciting to see, and then I'm like "Yes let's do that!" But that leap from... you know from the creative moment of "that would be really exciting and fun", to all the technical work of actually sourcing the photos, which is not as creative, and then tends to lead to people to be not as interested..." This example highlights that creative ideas did not always lead to the creation of new apps. It was important that volunteer-developers also had the time and energy to work on developing their new idea into an actual product.

In VAS, there were opportunities for volunteers to be creative by designing their own versions of the mini-games (these are games that volunteers can play while the simulation results are loading). One of the main scientists on the project said: "We have now enabled the customization mechanism that enables everyone to change anything in the game in a few steps. They just go to the project's Github page, fork it, and start editing things. Then they include their Github username in the game's URL and their changes appear. Since it is now very easy to make a custom version of a game component, I tested it in practice. I engaged the CERN summer students to work on a visualisation project [...] I saw that people followed the tutorials and had no problem creating their own customizations in a matter of minutes. So this is quite positive!" Similar to GeoTag-X, these development options engage expert users.

\subsubsection{The majority of volunteers feel that their task does not involve creativity- however, some creative thinking may be required to solve difficult tasks or gamify the project}

Most volunteers felt that their task did not involve much creativity. In GeoTag-X, they were supposed to simply state what they could see in each photo. However, there could be creative thinking involved when volunteers came across a photo that was difficult to analyse. One of the scientists suggests: "I think that when people are asked "is there an animal in this photo?" and it may be like a landscape photo and hard to tell, people can be a bit creative in seeing things [laughter] like they say "oh it could be a cow... or it could be a paper bag." So there's a little bit where people are invited to see what they want in the pictures. So from a technical point you would think there's not much creativity in analysing the pictures, but from a neuroscientist perspective in terms of the parts of people's brains lighting up, I think the 
things associated with creativity are in those few areas where people are going "hey could it be this thing? Or could it be this part of the question? Or could it be something not even listed?"

The task of geo-tagging photos was also thought to involve some creativity. One volunteeranalyser said: "Sometimes when you're selecting an area you have to draw the shape and that's slightly creative." The majority of volunteer-analysers did not attempt this task because it is more difficult and involves researching the photo's location. Again it appears that the more difficult the task is, the more likely the volunteer will need to think creatively about the different possible solutions. Also it appears that volunteer-analysers may be less willing to do more difficult (and more creative) tasks because they tend to be more time-consuming.

A further example of volunteers' creativity is "gamifying" the task to make it more fun. One of the volunteer-analysers described how three people in his work place were taking part in the data sprint and they decided to create a competition amongst themselves: "...then it got competitive as to who would do the most". By competing against each other and making the task more game-like they were able to increase their enjoyment of the task, proclaiming one person as "the winner" by the end of the data sprint, while also motivating each other to analyse more photos.

In VAS, the same task of tuning the parameters and running the simulation was interpreted as not creative or creative by different volunteers. Some volunteers viewed fitting the parameters as a creative activity because it involved elements of problem-solving and reflection. They had to experiment with the different parameters and figure out the best fit: "You use some kind of simulation, but the goal is to try to do it in the best way, in a way that you improve everything. And you have to think on how to do it properly, to take into account the different parameters. In a way I think it helps you develop your thinking process." However, other volunteers said that they did not view this task as creative because it just involved moving parameters around and did not require much thought: "...with the main features, the parameters, I didn't think I had to be creative there, it was just a matter of moving the parameters, there was no creativity involved." These examples show that different people can view the same task as creative or not creative, depending on how much effort they put into the task.

Volunteers could also be creative by writing explanations in the forum, as one scientist in charge of the project reports: "If they think the current explanations are not enough and they have a better idea to suggest, they can easily write their own explanation, or even post links to other resources. I actually saw some people posting links to Wikipedia, or other research papers, and stuff like that, explaining some terms they found difficult. So this is also something they can be creative at." In these examples, two main sources of creativity are the difficulty of the task (requiring further thinking) or the community (gamifying, writing explanations to help others to understand difficult concepts). 


\subsection{Discussion}

As the two projects offer very different tasks, in different scientific fields, and for different audiences (one interested by disaster management, the other one by particles physics), the creative activities that the volunteers talk about are unsurprisingly different. Considering the commonalities between the themes, we were able to categorise 4 main motivations for creative activities in virtual citizen science, see Table 2.

\section{Table 2. Motivations for Creativity in Virtual Citizen Science}

\begin{tabular}{ll}
\hline Motivation & Creative activities \\
\hline Part of the analysis task & Analysing ambiguous photos (GeoTag-X) \\
\cline { 2 - 2 } & Geo-tagging photos (GeoTag-X) \\
\cline { 2 - 2 } & Fitting the parameters (VAS) \\
\hline I want to help the scientists to collect useful data & Designing the apps (GeoTag-X) \\
\cline { 2 - 2 } & Suggesting improvements for the apps (GeoTag-X) \\
\cline { 2 - 2 } & Suggesting ideas for new apps (GeoTag-X) \\
\hline I want to help the community have more fun & "Gamifying” the task to make it more fun (GeoTag-X) \\
\cline { 2 - 2 } & Customizing mini-games (VAS) \\
\hline I want to help the community understand difficult & Writing explanations for others (VAS) \\
\hline
\end{tabular}

It is evident that the majority of creative activities are community-driven. Volunteers want to help the science team to collect useful data. They also want to help others in the community to have fun and to understand difficult concepts. Often they are using their own expertise (in the subject area, or in programming) to create these resources. They see a problem and they realise that they have the skills to help. Also being willing to collaborate with others is an important part of this. Otherwise (as in the case of suggesting new ideas in GeoTag-X) an idea might not lead to an actual creative product.

Sometimes creative processes are also involved in the task itself. These tend to be for more difficult tasks, which require extra thinking and additional research. However, we also found that volunteers were less willing to attempt difficult tasks. This supports Tinati et al. (2015), who also found that the speed and difficulty of the task can lead to participants getting bored and leaving. Considering these findings, we suggest some directions for the design of virtual citizen science projects. As creativity can be time-consuming, and therefore limited to a small number of volunteers, we suggest that the projects should offer simple tasks for a large number of volunteers, and more difficult tasks for a smaller number of highly engaged people. 
An active online community of volunteers may trigger creative actions; therefore, supporting such a community should be an additional goal for the scientists.

\section{COMMUNITY-BASED CITIZEN SCIENCE}

In this section we describe the two community-based citizen science projects: Synthetic Biology and Extreme Citizen Science. Then we present creativity themes for each project. Finally, we discuss similarities between the themes and propose 6 main motivations for volunteers' creativity.

\subsection{Pilot Projects}

\subsubsection{Synthetic Biology}

The Synthetic Biology pilot, developed by University Paris Descartes, aims to connect interested individuals to synthetic biology research. The main part of this pilot is the iGEM research competition, where research students carry out projects with members of the public. Scientists supervise teams of students that enter iGEM. The students typically have an academic background in biology, but this is their first time designing and conducting a synthetic biology research project involving members of the general public.
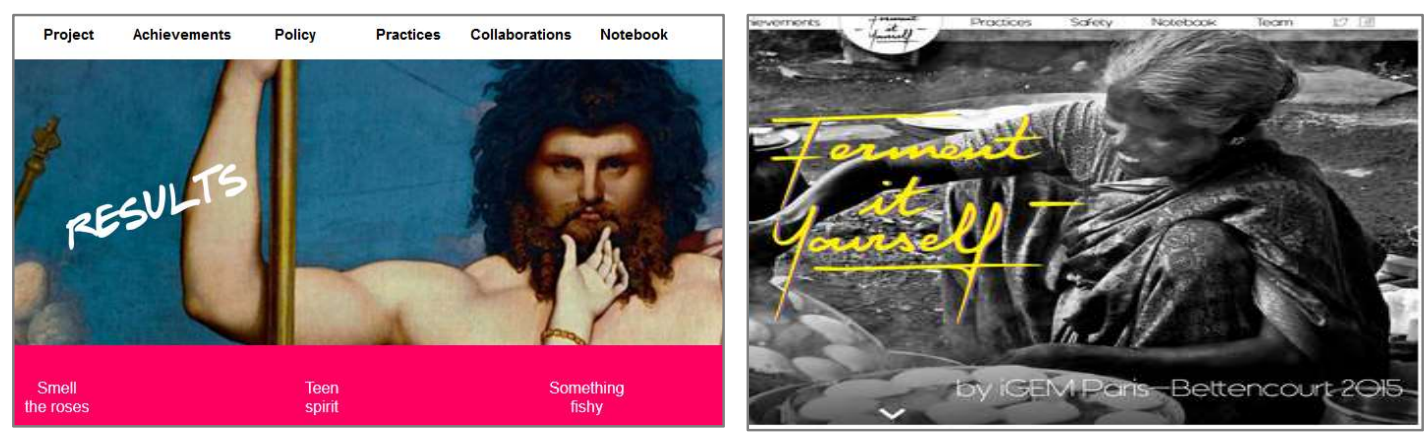

Figure 5. Screenshots of iGEM 2015 Team Paris Bettencourt website "The Smell of Us" (left image) and 2016 Team Paris Bettencourt website "Ferment it yourself" (right image).

The competition's research topic changes each year:

- In 2014, iGEM Team Paris Bettencourt's research topic was smell and body odour and they asked the general public to contribute by providing sweat samples. See Figure 5 (left image) for a screenshot of the 2014 team's website. ${ }^{12}$

\section{${ }^{12}$ http://2014.igem.org/Team:Paris_Bettencourt}


- In 2015, iGEM Team Paris Bettencourt's research topic was the nutritional content of fermented foods. They specifically targeted foods from southern India, as this region suffers high levels of malnutrition in rural areas. They presented the project to the general public at various events to get their feedback. See Figure 5 (right image) for a screenshot of the 2015 's team website ${ }^{13}$.

\subsubsection{Extreme Citizen Science}

The Extreme Citizen Science pilot, run by the UCL Extreme Citizen Science group, aims to introduce local community groups to Do-It-Yourself (DIY) tools and helps them to explore their own research questions. There are two components to this pilot:

- Playshops and workshops (DIY), where participants are introduced to DIY techniques such as kite-mapping and spectrometry;

- Air Quality Monitoring projects (AQM), where participants take measurements of air quality in their local area over several weeks.

The DIY playshops and workshops are organized by the London-based group Citizens without Borders and advertised on their Meetup webpage ${ }^{14}$. They utilize Public Lab's ${ }^{15}$ DIY tools and techniques to facilitate people's interest in DIY science and exploration. They run one-day workshops, where participants learn about a specific DIY technique, e.g. kite mapping (see Figure 6 - left image). They also run the Explorer of the World playshop series, where participants are encouraged to observe and explore the world around them over a series of six sessions. The Explorer of the World participants are encouraged to write blog posts about their experience and these are published on the Citizens without Borders website ${ }^{16}$.
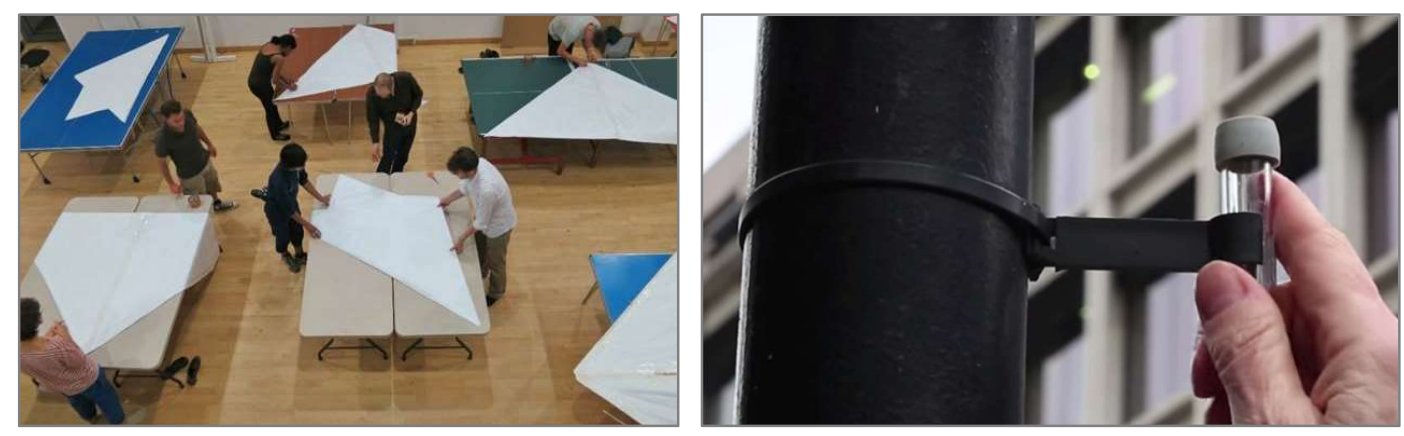

Figure 6. A photo of a kite-mapping workshop (left image) and a photo of a resident placing a diffusion tube on a nearby lamppost (right image).

\footnotetext{
${ }^{13} \mathrm{http} / / / 2015$. igem.org/Team:Paris Bettencourt

$14 \mathrm{http} / /$ www.meetup.com/Citizens-without-Borders/

15 https://publiclab.org/

16 https://citizenswithoutbordersdotcom.wordpress.com/
} 
The AQM projects are facilitated by Mapping for Change $e^{17}$ - a UCL-based social enterprise that specialises in the use of geospatial technologies to achieve social and environmental sustainability. Mapping for Change have worked with several local community groups in London, helping them to organise and carry out their own AQM projects (see Figure 6 - right image). Community groups have used this data to lobby for lower emission levels in their local area and to make changes to their behaviour in order to reduce their exposure to poor air quality.

\subsection{Creativity Findings}

In the presentation of our findings, we will focus on the convergences between the two community-based citizen science projects. Figure 7 offers an overview of creativity themes for the two projects.

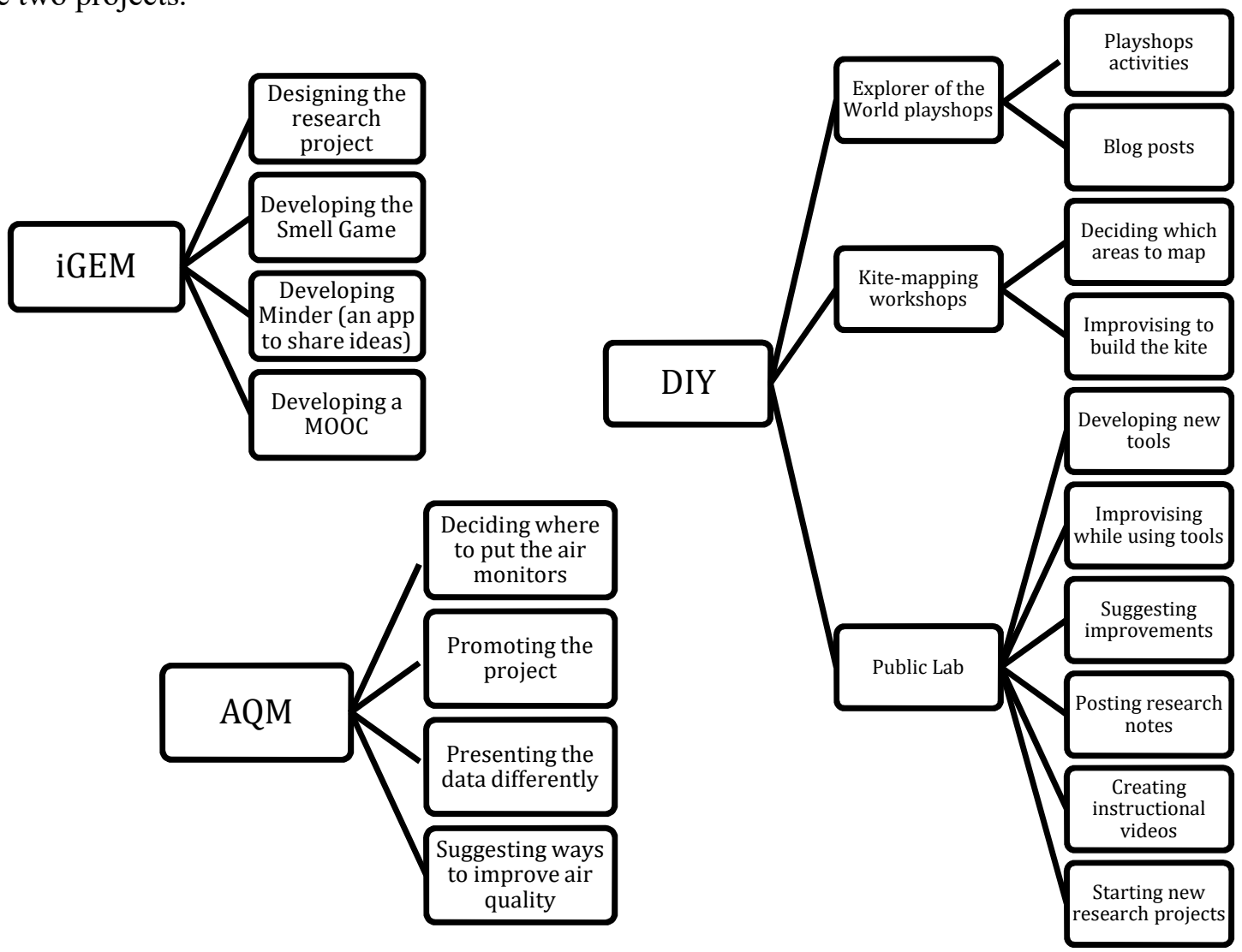

Figure 7. Creativity themes for Synthetic Biology iGEM and Extreme Citizen Science DIY and Air Quality Monitoring (AQM).

\section{${ }^{17}$ http://mappingforchange.org.uk/}


We identify 4 main findings: 1) volunteers who design their projects feel the most creative in their work; 2) volunteers are motivated to develop new tools to overcome obstacles and to make the project work better; 3) play is inherently creative; and 4) volunteers are creative in sharing their experiences and findings with others.

\subsubsection{Volunteers who design their projects feel the most creative in their work}

The iGEM students often use creative skills when they are designing their projects. There is a lot of brainstorming and discussion as each team needs to agree on a project idea and which scientific techniques they will use. As one of the scientists explains: "...overall they came up with "smell", that was the overall theme, but also with that they got to be creative by deciding what body odour thing they want to work, what smell thing they want to work on. And even within that they got to think about what technique would I like to use [...] So we gave them really many levels to be creative." Students talked about having the freedom to express their ideas: "...here we had the whole freedom of choosing our project, what parts we want to assemble into the project, we want to make videos or not, we want to make designs or not. In that way, it gives you the freedom to like express yourself, in a way that is different from a normal internship...” A collaborative team atmosphere was important for sharing ideas: “...it just happens very naturally, because everybody has ideas, and everybody shares them."

Similarly, in the AQM projects, the more the person was involved in designing the project, the more opportunities they had for creativity. For example, one participant explained that as her only involvement was hosting an air monitor in her home, she did not feel that she was doing anything particularly creative: "If your role in the project is to collect data, you should not need to be particularly creative in doing that." However, another participant who had to put air monitors up around her local neighborhood said that she did find that experience creative: "Yeah I mean if you're getting to dance around the neighbourhood and choose where to put up the air quality monitors there is an element of free form creativity in that." The key difference is that the latter participant had the freedom to choose where to place the monitors.

Likewise, in the kite-mapping workshops, participants could be creative in choosing what to map and how to map it. As the workshop facilitator explains: "I think the technical aspects are a bit less creative when they're being taught, but when they have to do it themselves then they immediately realise that it's the way they do it that matters, and that there is no correct way, and that gives them a lot of freedom to mould the technique in the way that fits them. So for example when we create maps on the online platform, yes the platform tools and settings are sort of fixed, but they can get creative in the way that they set up their map [...] because it's DIY they can still express the way that they want to do things. And because it's DIY it really forces them to think about the way that they themselves do things on their own." Similarly, one of the participants said: "I think because you have to choose the pictures, you have to reinvent the map. So it was like okay what shall I put here or there, or how can I run to take more pictures, where to go, it really spans your creativity." 
Another key aspect is that people are designing projects together. As one Public Lab community member explains, creative ideas often happen when people from different backgrounds work together: "The more people who talk, the more rich set of views that you get, and not always just thinking in your own way, it's just trying to open up perspectives, that people who are poor will have a different way of looking at the environment from people who are rich. And people who are handicapped may have a different way of looking at planning, how streets should be designed, from people who can walk normally. And the same with old people versus young people... so that's where community based planning comes in, and citizen science tries to mesh in with some of those community values."

\subsubsection{Volunteers develop new tools to overcome obstacles and to make things work better in the project}

DIY often involves on-the-spot problem-solving as participants encounter obstacles and need to think quickly to overcome them. For example, a kite-mapping participant described how he needed to improvise because he didn't have the exact materials to make his kite: "...making the kites was a creative exercise because we made mistakes and then we sort of had to improvise. Also, when I had to make the Picavet, I had to be creative again because I didn't use exactly the same materials as the person with the Research Note. I think it's also creative when something goes wrong during kite-flying, like a carabina gets broken or whatever, and you have to improvise and find different ways to attach things". Similarly, one of the members of the Public Lab community talked about problem solving while balloon-mapping: "I think there is a lot of creativity and a lot of on-the-spot thinking and problem solving, which really forces there to be creativity [...] just being able to find a place to launch a balloon is sometimes a real big challenge, which you don't always think about, because there's trees and traffic and buildings [...] we ended up trying all these different places, we ended up crossing the river and trying from this area, and ended up having to go over a barbed wire fence [...] I guess just things like that, that you don't always anticipate, that really force you to think outside the box and how you're going to accomplish your goal."

Sometimes this led to the development of new tools. For example, one Public Lab participant developed a new kind of giga-pan: "So I realised that I could put my current interest of gigapanning, taking high resolution panoramas stitched from multiple photos, combine that with aerial photography with kite or balloon so I would have a flying giga-pan." He explained that he enjoyed tinkering and puzzle-solving, and was interested to see whether he could figure out way to make things work better. He was also motivated by the thought that this was something that he could share with others in the community: "I wanted to make my own and make it very cheaply so that many people could use it so I will put instructions online with a bill of materials so that people can buy what they need, put it together and make it work."

Initial prototypes of new tools are often shared with the Public Lab community so that they can be tested out. One participant described how she enjoyed trying out new tools and suggesting improvements: “...so when MapKnitter 2 came along, I posted probably half a 
dozen Github issues [...] I had the pleasure of interacting with [name] as he was developing techniques, asking him questions about "Well how do you connect the camera? What about this rig or that rig?" And so I've made minor incremental adjustments and suggestions and improvements along the way that I think have been helpful to the Public Lab community."

In iGEM, it was suggested that time pressure led to creativity: "I mean, even more than giving you a chance to be creative, it's a necessity, right? So either because you don't have all the equipment that you're supposed to have, or because the time period is so short that you can't afford to spend two weeks just to do a minor experiment, right? So you have to be creative and think of other ways..." In addition to designing research experiments, the iGEM teams developed 3 creative tools - the Smell game, the Minder app, and the MOOC (Massive Open Online Couse). See Figure 8 for screenshots.
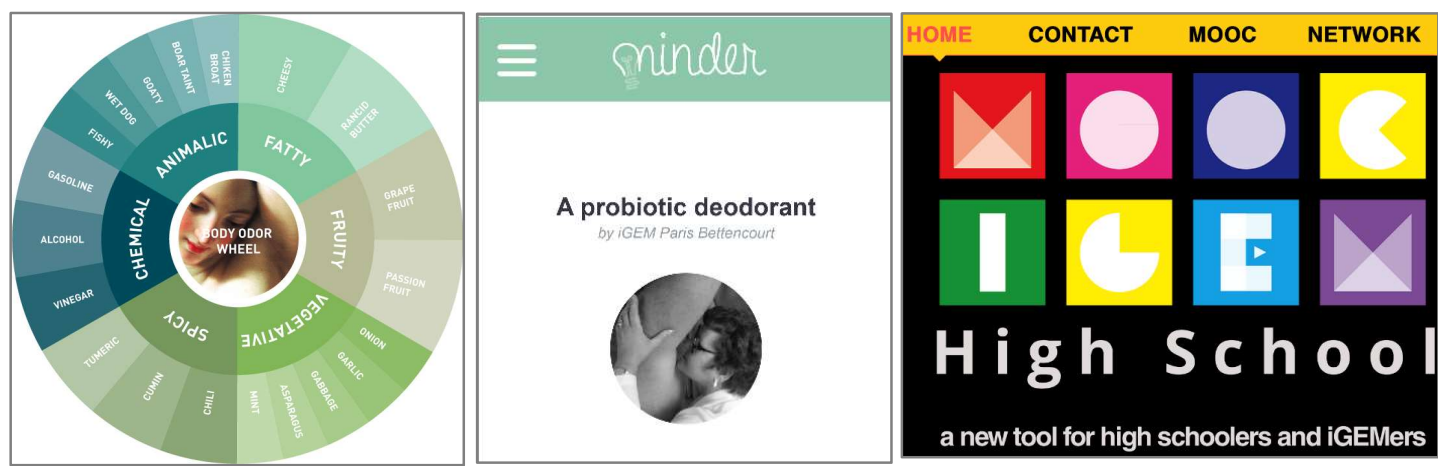

Figure 8. Screenshots of the Smell Game (left), Minder (centre) and the MOOC (right).

The Smell game was developed by 6 external students who wanted to be part of the Paris Bettencourt iGEM team, but unfortunately could not come to Paris because of lack of funds. They utilized their programming skills to develop the game, which they shared online, and this enabled them to still be a part of the team effort. As one scientist describes: "...they had a background in computer programming and bioinformatics. So they were able to analyse the data that came in and keep it in a databased for people. Something that no member of the core team had any understanding of doing, so it was pretty great that we found people that were able to do those kinds of things [...] And we made sure to give them credit for it, you know it's on the website, so that they can forever on their portfolios and resumes, they have now that they made this thing and it was showcased for this project and it was really great."

One of the students involved in developing Minder (an app to share ideas) explained that she joined the iGEM team because she wanted to be more interdisciplinary: "I was interested in many different things especially the connection between biology, medicine and informatics." She was able to use her programming skills to benefit the team. Again this emphasises the importance of people with different backgrounds and skillsets working together. Similarly, 
one of the students involved in developing the MOOC explained that he was motivated because of his passion for teaching: "I already worked with high schools in Spain, by bringing the students to my college, promoting biotechnology, because that was my degree in Spain, and I think it's more important than most people do when they think of science..." Having this passion and previous experience in education gave him the confidence to push for the MOOC to be developed.

\subsubsection{Play is inherently creative}

Allowing citizens to be imaginative and to express themselves is an important part of DIY. The Explorer of the World playshop series aims to encourage people to grow in confidence in expressing themselves and asking questions about the world around them. The playshop facilitator explains that creativity is central to these activities: "...the playshops are all based on expanding people's creative potential. The playshops use different media for people to express the way they are learning, what they're experiencing or knowing about, through for example artistic expressions of photography. So that leads to many different outlets for the way that they can express what they're thinking, or going through, or learning, or want to say about things they're learning, or their relationship with what they're building either within themselves or other people or the surrounding environment..."
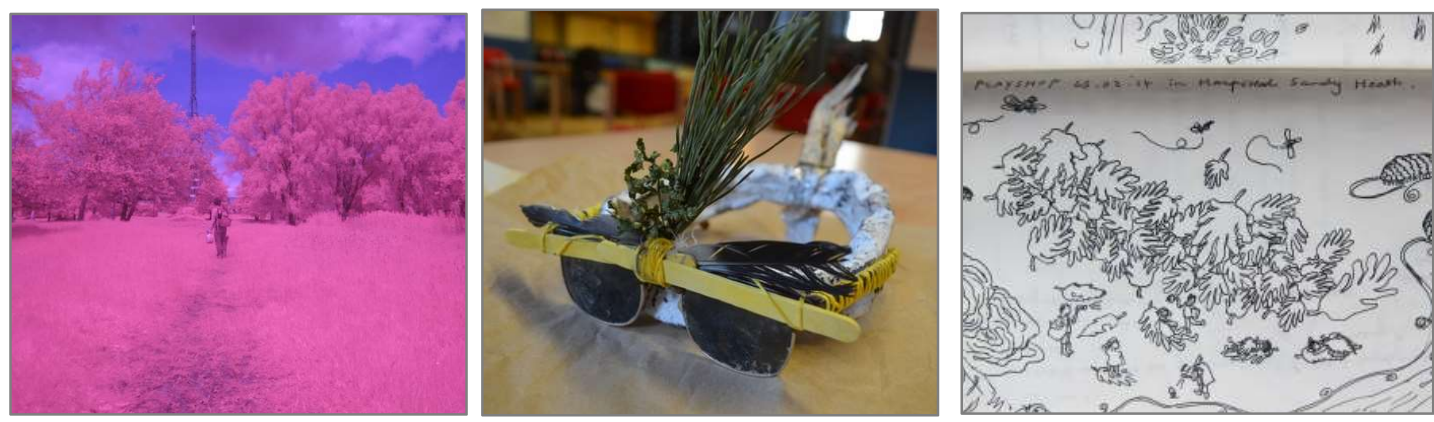

Figure 9. Photos of creative work made during playshops: infra-red photography (left), a sculpture from repurposed materials (centre), a drawing of the environment (right).

Some playshop activities involve the use of Public Lab tools. For example, the facilitator described how participants explored infra-red photography in one of the playshops: "people started to get very curious and creative about the way that they would take pictures, asking questions about taking photographs in direct sunlight or no direct sunlight and what difference that would make. Also creative in the way that they captured the imagery [...] So within the very constrained technical use of an infrared camera they were still creating in the way they were using the tool which then led to ask more questions about its use and applications." Other playshop activities include making collages, sculptures, and improvisation theatre. See Figure 9 for a few photos of creative work made during playshops. 
One participant suggested that art and play are less intimidating for people to engage with (compared to computer science) because there are no right or wrong answers. Another participant suggested that being with other people and sharing the experience helped him to elevate his creativity: "Once you're with people, and around people, and discussing with people, even just being in the same room, where we weren't really communicating about what we were doing. But if you see people doing things in different ways, and that kind of elevates your own approach. So it's nice to be in the same place with other people doing it, otherwise it's very easy for your own neuroses to take over..." A further factor is that the activities build up over time, helping participants to feel more comfortable with opening up to each other and sharing playful experiences.

\subsubsection{Volunteers are creative in sharing their experiences and findings with others}

Sometimes playshop participants felt inspired to write blog posts about their experiences after they attended a playshop. They wanted to have a record of what they did and how they felt and share this with others: "Because my mind was moved, my feelings, my emotions moved and I wanted to record it. I have to - yeah, it's to share, but I'm learning to share my feelings still, so it doesn't come naturally to just announce to the world, but I just wanted to record that my mind was moved in a nice way..."

Similarly, in Public Lab, participants wrote up their technological developments and their research projects as research notes and posted these on the Public Lab website. One participant explained that she wanted to have an online record for her own use and to share with others: "Every little thing I go I try to make a little story out of and post and I like to think that they're helpful to the community, but I know that they are helpful to me because, you know just like when you're a scientist you need to keep a lab book or a log book or a field notebook so you have a record of what you've done..." Another participant emphasised the importance of sharing with others so that they could read about new findings and to give feedback: "...we like to make sure that the whole project is told, because it's an important part of inviting people into the process. And then, also, it's a form of give and get, so when you publish you ask for help, you ask for input and insights and you ask for people to critique and support you as you're getting along and you're also opening yourself up to others, to allow others to share in the ownership of the process in the development." In addition to research notes, some community members also created instructional videos to help people without technical backgrounds to use their software: "I posted a video actually, installing the software from completely nothing [...] it takes about ten minutes. I'm really excited."

One participant explained that as he became more familiar with the Public Lab community, through attending various events and talking to other community members, he felt more confident to share his ideas and to post his own research notes. This suggests that perhaps it takes a certain amount of self-confidence before volunteers feel comfortable posting online: "I think that's what started to change, I felt more comfortable putting my own ideas around solutions because I got some positive feedback in those in person meetups and then with the 
interactions that I had online. So then I took on, I think, a more significant role in developing some of these technologies, so testing out some of the techniques and the cameras and the infra-red photography project for example, and then posting these tests online and some instructions online, and starting to feel like that was going to be okay and people weren't just going to just say this guy doesn't understand anything about this stuff."

A few participants described how they were contacted by other community members who had read their research notes, and this led to arranging meetings and the start of new projects. For example, one participant said: "He saw my research notes there and sent me an email and said 'Hey I'm just five miles away, we should meet.' So we made a plan, we met to fly kites and he was interested in that too as well as remote sensing. So we're communicating right now about infrared filters." Through connections within the community, participants were able to collaborate and design technologies that they might not have been able to work on otherwise: "I used my networking with Public Lab to make it possible to do things that I wouldn't be able to do nearly as easily on my own."

In AQM, there are various creative ways in which volunteers promote their projects to their local communities. One participant described giving away plants at a community fair to raise awareness. Another participant talked about promoting her project using social media: "if you're promoting it in social media, if it was to be in a tweet or on Facebook, you need to make that eye-catching..." Designing t-shirts and having family-friendly campaigns were another way of promoting the project to the local community and also to the press: "...we've got $t$-shirts we produce for kids to wear, and we distribute flyers at events. So the kids all wear these black and white t-shirts with "smog off" and "diesel no tar" and "clean air tastes good", and they pass these out to passers-by while the parents just hang around. So that's good, one of our big events we do to raise awareness around the public..."

It is also important to present data in a way that is eye-catching and user-friendly for the general public. One AQM participant explained that she created an alternative map to the one that was provided by Mapping for Change because she wanted a different colour scheme and she wanted to be able to share it more widely: "Well I suppose creating the map for me was a fairly creative thing. It's not something that I had ever done before so I learned from how to do that [...] I wanted to be able to share it more widely and obviously everyone's got Google Maps access, but also I wasn't keen on the colour scheme, so I wanted to use one that I felt highlighted the problem a bit more..." Another participant explained that sometimes maps can be too "data heavy". Instead of presenting the whole map, she selected the key findings and presented these on a flyer and poster: "And then once you get the data, the greatest creativity from us comes in the production of the flyer. The flyer is critical, it's the point of communication between us and the parents we want to reach, so what we do is produce a flyer and we also produce a poster as well. The maps are alright but the maps to be honest are data heavy. They are interesting to parents that walk around those schools, because they want to see where the most polluted roads are, but if someone is just walking past a poster they're not 
necessarily going to stop and look at that. So you need to make the whole thing really attractive and eye catching."

\subsection{Discussion}

Again the creative activities that volunteers talk about are different because the projects involve very different tasks, in different scientific fields, and with different communities. Considering the commonalities between the themes, we were able to categorise 7 main motivations for creative activities in community-based citizen science, see Table 3.

\section{Table 3. Motivations for Creativity in Community-based Citizen Science}

\begin{tabular}{|c|c|}
\hline Motivation & Creative activities \\
\hline \multirow[t]{4}{*}{ Part of the research task } & Deciding which areas to map (DIY) \\
\hline & Improvising to build the kites (DIY) \\
\hline & Improvising while using tools (DIY) \\
\hline & Deciding where to put the air monitors (AQM) \\
\hline $\begin{array}{l}\text { I want to open myself up to new ways of seeing and } \\
\text { experiencing the world around me }\end{array}$ & Playshop activities (DIY) \\
\hline \multirow[t]{2}{*}{ I want to do new and interesting research } & Designing the research project (iGEM) \\
\hline & Starting new research projects (DIY) \\
\hline \multirow{4}{*}{$\begin{array}{l}\text { I want to help the research team/community to collect } \\
\text { useful data }\end{array}$} & Developing Minder (iGEM) \\
\hline & Developing the Smell Game (iGEM) \\
\hline & Developing new tools (DIY) \\
\hline & Suggesting improvements (DIY) \\
\hline \multirow{2}{*}{$\begin{array}{l}\text { I want to share my experiences/findings with the } \\
\text { community }\end{array}$} & Blog posts (DIY) \\
\hline & Posting research notes (DIY) \\
\hline \multirow[t]{3}{*}{ I want to help more people join the community } & Promoting the project (AQM) \\
\hline & Creating instructional videos (DIY) \\
\hline & Developing a MOOC (iGEM) \\
\hline \multirow[t]{2}{*}{ I want to improve my local area } & Promoting the project (AQM) \\
\hline & Suggesting ways to improve air quality (AQM) \\
\hline
\end{tabular}

Similar to virtual citizen science, we see that the majority of creative activities in communitybased citizen science are community-driven. However this time, motivations are more 
personal. People are not volunteering just to help scientists, but because they want to help their local communities. iGEM students and Public Lab community members design their own research projects to investigate topics that they find interesting. AQM volunteers carry out their research because they want to improve air quality in their local area.

It is evident that the more a volunteer is involved in setting up the research project, the more likely they are to experience creative processes in their work. AQM volunteers who were involved in promoting the project (creating posters, flyers, etc.) were more likely to view their work as creative compared to those who just hosted air monitors in their homes. Playshop participants who were given open tasks (such as to create artwork) were more likely to view their work as creative compared to kite-mapping workshop participants who had to follow technical guidelines to create their kites.

Another key finding is that as volunteers become more familiar with the community, they become more confident to share their ideas. We see examples of this in both the playshops (sharing artwork, sharing blogs) and Public Lab (sharing research notes). In line with previous research (Kop \& Carroll, 2012), this suggests that learners must feel comfortable in their learning environment and have trust in their fellow participants before they build the confidence to create and share creative artefacts. Therefore, providing a supportive environment and building a sense of community is important for encouraging creativity. It is also important to encourage participation from people with different backgrounds, to ensure a range of different skills and perspectives.

\section{CONCLUSION}

In our research we have shown that volunteers experience many different kinds of creativity in citizen cyberscience. We conducted 96 interviews in total: 86 with volunteers and 10 with scientists. To our knowledge, this is the largest interview dataset in citizen cyberscience research. Our results reveal several creative activities that are a result of active involvement in citizen cyberscience: discussing ideas, suggesting improvements, development of new technologies, gamification, artwork, creative writing, outreach activities, and the development of new research projects. We conclude that the majority of creative products are communityrelated. Most creative activities do not lead to scientific discoveries; however, they are still important for a project's success. Creative products come from the wish to optimize one's own activity: making things work better for themselves, and therefore, potentially for all members. Creative products help the project to operate better, by solving project problems. Creative products also enhance the community life, helping volunteers to enjoy the project more. In future research, it would be interesting to explore creativity in other citizen science contexts.

\section{ACKNOWLEDGEMENTS}

We would like to thank all of our interview participants. Thank you to Muki Haklay, Francois Grey, and Ariel Lindner, for their leadership and encouragement throughout Citizen Cyberlab. 
Thank you to our reviewers for their valuable feedback. Also a special thanks to the Human Computation journal editors, Egle Marija Ramanauskaite and Pietro Michelucci, for their positive support and advice. This research was funded by the EU project Citizen Cyberlab (Grant No 317705). Charlene Jennett is currently funded by the Open 3D project (EPSRC grant EP/M013685/1).

\section{REFERENCES}

Bonney, R., Ballard, H., Jordan, R., McCallie, E., Phillips, T., Shirk, J. and Wilderman, C. (2009). Public participation in scientific research: Defining the field and assessing its potential for informal science education. A CAISE Inquiry Group Report, Center for Advancement of Informal Science Education (CAISE), Washington, DC, Technical Report. Retrieved from http://www.informalscience.org/public-participation-scientific-researchdefining-field-and-assessing-its-potential-informal-science

Braun, V., and Clarke, V. (2006). Using thematic analysis in psychology. Qualitative Research in Psychology 3 (2), 77-101. Retrieved from http://www.tandfonline.com/doi/abs/10.1191/1478088706qp063oa

Cardamone, C., Schawinski, K., Sarzi, M., Bamford, S. P., Bennert, N., Urry, C., Lintott, C., Keel, W. C., Parejko, J., Nichol, R. C., et al. (2009). Galaxy zoo green peas: Discovery of a class of compact extremely star-forming galaxies. Monthly Notices of the Royal Astronomical Society 399 (3), 1191-1205. doi>10.1111/j.13652966.2009.15383.x

Cohn, J.P. (2008). Citizen science: Can volunteers do real research? BioScience, 58 (3), $192-197$. doi>https://doi.org/10.1641/B580303

Cooper, S., Khatib, F., Makedon, I., Lu, H., Barbero, J., Baker, D., ... others. (2011). Analysis of social gameplay macros in the Foldit cookbook. In Proceedings of the 6th International Conference on Foundations of Digital Games (FDG'11), 9-14. doi>10.1145/2159365.2159367

Dickinson, H. (2011). Citizen science: Science needs YOU! The Naked Scientists. Retrieved from https://www.thenakedscientists.com/articles/features/citizen-science-science-needs-you

Haklay, M. (2013). Citizen science and volunteered geographic information: Overview and typology of participation. In D. Sui et al. (Eds.), Crowdsourcing Geographic Knowledge: VGI in Theory and Practice, 105-122. Springer Netherlands. doi>10.1007/978-94-007-4587-2_7

Jennett, C., Kloetzer, L., Schneider, D., Iacovides, I., Cox, A. L., Gold, M., Fuchs, B., Eveleigh, A., Mathieu, K., Ajani, Z., and Talsi, Y. (2016). Motivations, learning and creativity in online citizen science. Journal of Science Communication, 15 (03), A05. Retrieved from https://jcom.sissa.it/archive/15/03/JCOM_1503_2016_A05

Kop, R., \& Carroll, F. (2012). Cloud computing and creativity: Learning on a massive open online course. European Journal of Open, Distance and E-Learning. Retrieved from http://www.eurodl.org/index.php?article=457

Literat, I. and Glaveanu, V.P. (2016). Same but different? Distributed creativity in the internet age. Creativity: Theories - Research - Applications, 3 (2), 330-342. Retrieved from https://www.degruyter.com/view/j/ctra.2016.3.issue-2/ctra-2016-0020/ctra-2016-0020.xml

Maciuliene, M. and Skarzauskiene, A. (2016). Emergence of collective intelligence in online communities. Journal of Business Research, 69, 1718-1724. http://dx.doi.org/10.1016/j.jbusres.2015.10.044

Mapping for Change (2014). Science in the City: Monitoring air quality in the Barbican. Retrieved from https://www.cityoflondon.gov.uk/business/environmental-health/environmental-protection/airquality/Documents/barbican-final-report-13012015.pdf

Tinati, R., Kleel, M.V., Simperl, E., Luczak-Roesch, M., Simpson, R., and Shadbolt, N. (2015). Designing for citizen data analysis: A cross-sectional case study of a multi-domain citizen science platform. In Proceedings of the 33rd Annual ACM Conference on Human Factors in Computing Systems (CHI'15), 4069-4078. doi $>10.1145 / 2702123.2702420$

Vitos, M., Stevens, M., Lewis, J., and Haklay, M. (2013). Making local knowledge matter: Supporting non-literate people to monitor poaching in Congo. In Proceedings of the Third Annual Symposium on Computing for Development (DEV'13). doi>10.1145/2442882.2442884

Wiggins, A., and Crowston, K. (2011). From conservation to crowdsourcing: A typology of citizen science. In Proceedings of the 44th Annual Hawaii International Conference on Systems Sciences (HICSS'11), 1-10. http://dx.doi.org/10.1109/HICSS.2011.207 